\title{
On the use of reconstructive aging techniques for assessing seagrass demography: a critique of the model test of Jensen et al. (1996)
}

\author{
Michael J. Durako ${ }^{1, *}$, Carlos M. Duarte $^{2}$ \\ ${ }^{1}$ Florida Marine Research Institute, 100 Eighth Ave. S.E., St. Petersburg, Florida 33701, USA \\ ${ }^{2}$ Centro de Estudios Avanzados de Blanes, CSIC, Cami de Santa Barbara s/n, E-17300 Blanes, Girona, Spain
}

The paper by Jensen et al. (1996) reports an attempt to test the predictive abilities of a population model based on the use of reconstructive techniques (Duarte et al. 1994). The population model that was tested utilizes the age distributions of individual seagrass shortshoots collected at least once per year, from which annual gross shoot recruitment rates $\left(R_{\mathrm{gross}} \mathrm{yr}^{-1}=\ln N_{\mathrm{l}}\right.$ - $\ln N_{t>1}$, where $N_{t}$ is the total number of shoots and $N_{t>1}$ is the number of shoots older than a year) and instantaneous mortality rates $[M$, derived from the number of shoots in consecutive cohorts and estimated by fitting the equation $N(t)=N(0) \mathrm{e}^{-M t}$ to observed data, where $N(t)$ is the number of shoots at time $t, N(0)$ represents the number of shoots at $t=0$, if $t=1$ yr then the units for $M$ are $\mathrm{yr}^{-1}$ ] are calculated (Duarte et al. 1994). Shoot ages are determined by counting the number of leaves and leaf scars for each shoot. The interval between the formation of consecutive leaf scars is termed the plastochron interval (PI; Erikson \& Michelini 1957). Conversion of leaf-scar PIs to absolute time can be accomplished directly using the leafpunch productivity method (Patriquin 1973, Brouns 1985), and indirectly by reconstructive methods such as determining the differences in numbers of leaf scars between successive annual cohorts (large numbers of shoots of similar age) divided by 365 (Duarte et al. 1994).

Jensen et al. (1996) correctly point out that the calculation of mortality using the exponential decline of numbers of living shoots with age assumes constant age-specific shoot mortality and recruitment rates. However, they make no attempt to test if these assumptions are satisfied. An exponential model with age-dependent mortality rates can also be fitted to the population age data, but, in the absence of evidence that shoot mortality is age dependent, the simple expo-

\footnotetext{
•E-mail: durako_m@sellers.dep.state.fl.us
}

nential model provides the most parsimonious and robust model (Cox \& Oates 1984). In addition, recruitment and mortality in plants are typically more correlated with plant size, rather independently of age (Sarukhán et al. 1985). Plots of residuals from mortality curves versus shoot-cohort ages and total-sample shoot ages (the approach used by Jensen et al. 1996) for Thalassia testudinum collected from Rabbit Key Basin during 1989 and 1990 from Durako (1994) are shown in Fig. 1. Regression slopes for all of the plots are not significantly different from 0 , suggesting no age-dependent bias in the annual mortality estimates derived from the simple exponential model. Alternatively, Duarte et al. (1994) recommend that mortality estimates should be derived from the distribution of age at death (i.e. that of ages of dead shoots) to avoid the assumption of constant mortality. This alternative was not considered in the model test by Jensen et al. (1996)

Differences between gross recruitment and mortality estimates $\left(R_{\text {net }}=R_{\text {gross }}-M\right)$ can be used to assess whether a population is increasing $\left(R_{\text {gross }}<M\right)$, declining $\left(R_{\text {gross }}>M\right)$, or in steady state $\left(R_{\text {gross }}=M\right)$, at the time of sampling (Duarte et al. 1994). Net recruitment may change from year to year because of annual changes in recruitment and mortality rates. Restricting inferences derived from demographic statistics to within a year-to-year (i.e. annual) time frame is a fundamental concept on the use of these population models (Ricker 1975, Duarte et al. 1994). In this regard, Durako (1994) reported significant annual (1989 vs 1990) fluctuations in both $R_{\text {gross }}$ and $M$ in 3 Thalassia testudinum populations in Florida Bay resulting in dramatic year-to-year differences in the magnitude and direction of calculated $R_{\text {net }}$ (Table 1).

Population half-life $\left[T_{1 / 2}=\ln (2) / M\right]$ can also be calculated from age-distribution data. Jensen et al. (1996) state that the mortality estimate is calculated from an exponential decay equation and as such the half-life 

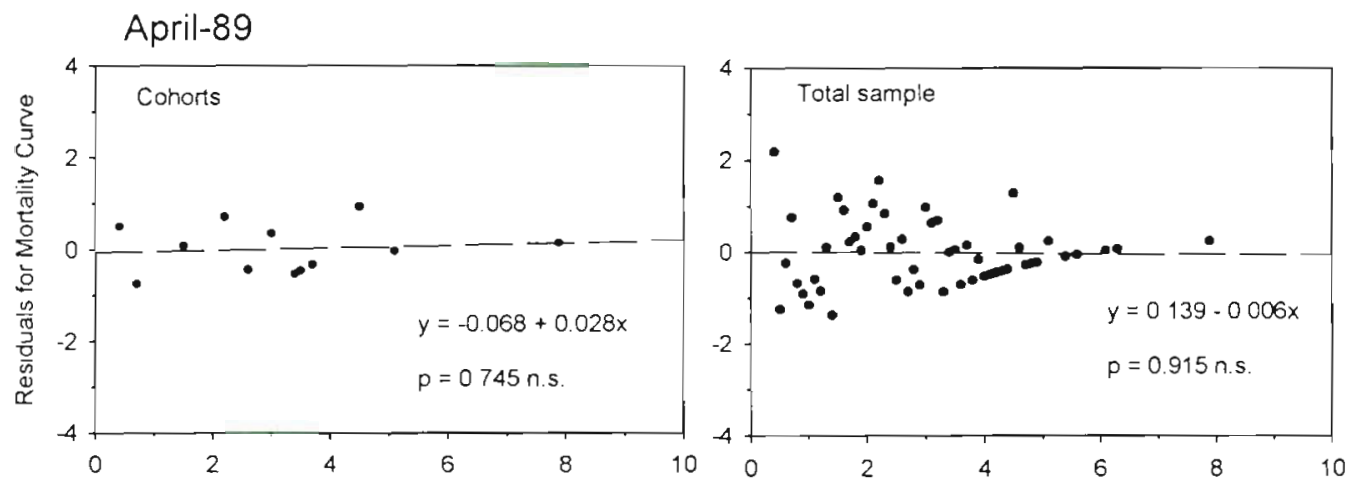

April-90

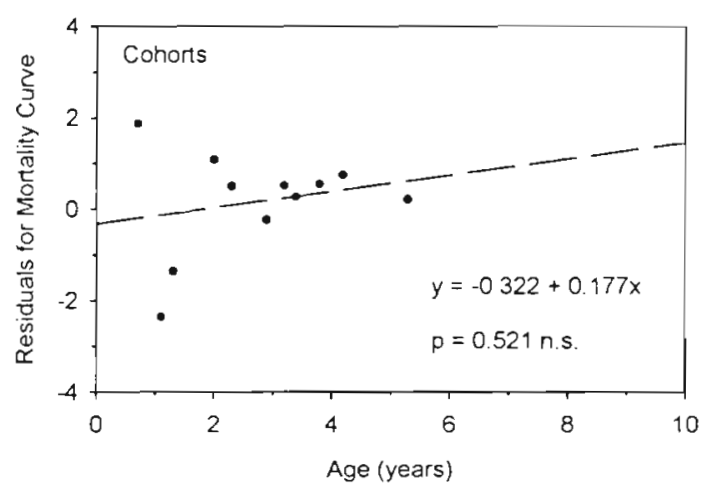

equation, with mortality in the denominator (Durako 1994), will always de facto present a picture of a declining population'. This statement is wrong. The exponential model assumes that rates are per capita and half-life simply describes the time in which half of the recruited shoots will be dead. The exponential decline curve for shoot ages does not necessarily mean that a population is declining, since estimates of net recruitment inferred from these distributions can be positive and indicative of expanding populations (Duarte \& Sand-Jensen 1990).

Predicting population growth or decline from demographic statistics-the test. Demographic statistics and population model 'predictions' originally calculated for populations of Thalassia testudinum in Florida Bay experiencing severe die-off (Durako 1994) were tested by Jensen et al. (1996) using data collected over 4 yr later, from different sites, during a different time of year, and using different sample collection and handling techniques. The latter authors also used a different model to calculate mortality (total-sample population versus cohorts). Specifically, Jensen et al. (1996) compared demographic and quantitative (i.e. shoot density) statistics calculated from data that they collected in Rabbit Key Basin in Florida Bay during June 1994 to demographic statistics calculated from data

Table 1 Thalassia testudinum. Short-shoot density, demographic characteristics and predicted and measured changes in shortshoot densities from 3 Florida Bay basins (modified from Durako 1994)

\begin{tabular}{|c|c|c|c|c|c|c|}
\hline \multirow[t]{2}{*}{ Parameter } & \multicolumn{2}{|c|}{ Rabbit Key } & \multicolumn{2}{|c|}{ Rankin Lake } & \multicolumn{2}{|c|}{ Johnson Key } \\
\hline & April 1989 & April 1990 & April 1989 & April 1990 & April 1989 & April 1990 \\
\hline \multicolumn{7}{|l|}{ Demographic characteristics } \\
\hline Gross recruitment $\left(\mathrm{yr}^{-1}\right)$ & 0.39 & 0.55 & 0.84 & 1.51 & 0.42 & 0.71 \\
\hline Mortality $\left(\mathrm{yr}^{-1}\right)$ & 0.43 & 0.83 & 1.35 & 2.18 & 0.37 & 0.87 \\
\hline Net shoot production $\quad\left(\mathrm{yI}^{-1}\right)$ & -0.04 & -0.28 & -0.51 & -0.67 & 0.05 & -0.16 \\
\hline $\begin{array}{l}\text { Predicted density change for } \\
\text { following year }(\%)\end{array}$ & -4 & -24 & -40 & -49 & +5 & -15 \\
\hline \multicolumn{7}{|l|}{ Quantitative characteristics } \\
\hline Short-shoot density $\left(\mathrm{m}^{-2}\right)$ & $391 \pm 22$ & $382 \pm 20$ & $340 \pm 27$ & $263 \pm 17$ & $358 \pm 17$ & $315 \pm 16$ \\
\hline Measured density change (\%) & -2 & nd & -22 & nd & -12 & nd \\
\hline
\end{tabular}


collected in a previous study of seagrass die-off during April 1989 and April 1990 (Durako 1994). Jensen et al. (1996) then claim to test the robustness of the 'predictions' of Durako (1994) for continuous shoot-density declines.

Jensen et al. (1996) correctly state that the 'construction of an age distribution is the first step in the description of a population'. These authors also point out the need to measure the PI in demographic analyses, but then make no effort to measure it themselves. All of the demographic statistics presented by Jensen et al. (1996) are based on the conversion of leaf-scar data (PIs) into shoot ages using an annual PI calculated from a completely different data set (18.2 d from Durako 1994). This PI value was calculated from leafpunch productivity data collected every 2 mo over the period from April 1989 to April 1990 from sites in Rabbit Key with visible seagrass die-off (Durako 1994). The use of this PI value in the study of Jensen et al. (1996) is inappropriate for several reasons. First, the duration of PIs can exhibit considerable spatial and temporal variability resulting from environmental influences (Duarte et al. 1994, Durako 1994). For example, PI estimates for Thalassia testudinum populations in 3 basins in Florida Bay ranged from 12.9 to $25.6 \mathrm{~d}$ over a 1 yr period (Durako 1994). Second, most of the shoots present in the Rabbit Key population in 1994 were produced during the $4 \mathrm{yr}$ interval between the Durako (1994) study and the sampling by Jensen et al. (1996). Any changes in the PI of a population that is experiencing perturbation (e.g. seagrass die-off) would confound the demographic statistic estimates obtained by Jensen et al. (1996). The absence of seasonal or annual patterns is the suggested reason why Jensen et al. (1996) apparently made no attempt to estimate PIs from their own data. Although this would preclude the use of the cohort method, no corroborating evidence or test of this assumption is provided. Seasonality in seagrass growth has been identified in all seagrass populations where its presence has been tested (see discussion on time-series analyses in Duarte et al. 1994). That shoot cohorts were identified by Durako (1994) indicates that rhizome growth shows seasonal variation in Florida Bay. Seasonal changes in internodal sequences, such as reported for Thalassia testudinum in the Mexican Caribbean (Marbá et al. 1994) must also exist. Inferred values of mean annual PI can be validated by comparisons with direct methods (i.e. leaf punching), by using the sequence of internodal length (filtered of subseasonal and interannual variation; Duarte et al. 1994) in long horizontal or vertical rhizome fragments, and from modes in the time since flowering (inferred from the position of flower scars; Gallegos et al. 1992, 1993, van Tussenbroek 1994a, b)
Jensen et al. (1994) correctly point out that the effect of spatial variability on shoot demographic characteristics may be important and has not been evaluated. However, spatial variability and scale-dependent effects are not problems intrinsic to demographic statistics obtained using the reconstructive method. Most of the present knowledge on the dynamics of seagrasses is based on quadrat or core samples (e.g. biomass, standing crop, leaf mark productivity, nutrient cycling, etc) and subsequent extrapolations to larger scales. In their comparative study, Jensen et al. (1996) state that, in addition to testing the predictions of Durako (1994), they address the question of 'sampling design relative to spatial variability'; yet they used a haphazard sampling design and sample-collection methods completely different from the earlier study. The sampling design of Durako (1994) subdivided this large basin (>3200 ha, not 52.5 ha as stated by Jensen et al. 1996, see Fig. 1 in Robblee et al. 1991) into a $0.5 \mathrm{n}$ mile interval sampling grid with each grid intersection point being assigned a station number. Samples of Thalassia testudinum were obtained at the first 3 randomly chosen grid points - with visible seagrass die-off patches. Sampling locations at each station were stratified by collecting plant material within $20 \times$ $20 \mathrm{~cm}$ quadrats positioned at $1 \mathrm{~m}$ intervals along a $4 \mathrm{~m}$ long transect extending from $2 \mathrm{~m}$ into a die-off patch to $2 \mathrm{~m}$ into an apparently healthy bed (Durako 1994). In contrast, Jensen et al. (1996) explicitly state that 'there was no attempt to stratify sampling according to seagrass coverage, or to target highly disturbed or recently colonized areas'. Jensen et al. (1996) sampled 3 haphazardly selected stations within Rabbit Key Basin (scale of station separation unknown); at each station, an area of $115 \mathrm{~m}^{2}$ was haphazardly sampled by taking thirty $15.3 \mathrm{~cm}$ diameter cores. This sampling design also failed to address known environmental and biological gradients in Rabbit Key basin (Zieman et al. 1989). Despite this great disparity in sampling and analyses, the results obtained by Jensen et al. (1996) are remarkedly similar to those of Durako (1994) and an objective evaluation of the data should not have failed to note this similarity.

Jensen et al. (1996) interpret their results as conflicting with changes predicted by Durako (1994). This conclusion is based on misrepresentation of the data presented in the earlier study, a fundamental misapplication of the demographic statistics derived from population age-structure data (year-to-year), and improper use of statistical analyses. Even without these analytical problems, the specific comparison of shoot densities measured by Durako (1994) with those reported by Jensen et al. (1996) represents an inappropriate test of the earlier study's predictions because, as stated above, the sampling sites and criterion for site 
selection differed (e.g. fixed sampling grid and presence of visible die-off vs haphazard sampling), the methods of collection differed (quadrat harvesting vs core sampling), and the densities were measured in different seasons (April vs June). Durako (1994) only sampled sites 'with visible die-off patches'. Seagrass die-off is defined by a significant loss of shoots, i.e. a reduced shoot density (Robblee et al. 1991, Durako 1995). Seasonal changes in shoot density can also be significant in this region (Zieman 1975, Durako 1995) and could, additionally, have confounded the comparisons.

Jensen et al. (1996) state that Durako (1994) predicted that the population of Thalassia testudinum in Rabbit Key would exhibit a continuous decline in seagrass shoot density of 15 to $49 \% \mathrm{yr}^{-1}$. This statement is wrong. Durako (1994, p. 64) stated, based on the age structure data from the 3 basins sampled (Rankin Lake, Johnson Key Basin, and Rabbit Key Basin), that 'shoot densities in 1991 are predicted to be 15 to $49 \%$ lower than those in 1990 with the greatest declines occurring in the JKB (Johnson Key Basin) and RKB (Rabbit Key Basin) populations'. Jensen et al. (1996) totally ignored the possibility that changes in recruitment and mortality patterns in the intervening 4 yr between the 2 studies may have influenced their results; they also imply that Durako (1994) meant to do the same. This is most disturbing since one of the major points of Durako (1994) was to contrast the significant year-to-year variability in recruitment and mortality (Table 1).

An appropriate test of the predictive ability of the population model should compare calculated net shoot production and the relative change in shoot densities between 2 consecutive years. This test can be conducted using data presented in Durako (1994). Table 1 presents several demographic and quantitative statistics originally presented in Table 2 and Fig. 7 of Durako (1994). The net shoot-production estimate for the Rabbit Key basin population of Thalassia testudinum, based on samples collected during April 1989, 'predicts' that shoot densities will be $4 \%$ lower in 1990. The measured decline in mean shoot densities using the same sampling strategy (but not the same sample sites) was $2 \%$. For the Rankin Lake and Johnson Key populations, the 'predictions' for shoot density changes were $-40 \%$ and $+5 \%$; measured density changes were $-22 \%$ and $-12 \%$, respectively. Except for the Johnson Key population, the model reflects the population status fairly closely. The change in population status in Johnson Key, from approximately steady-state to decreasing, does not invalidate the model, but reflects the increase in mortality rate associated with the spread of die-off during this time period (Roblee et al. 1991, Durako et al. 1992, Durako 1994)
Spatial variability and data collection. In addition to their model test, Jensen et al. (1996) examined the effects of spatial variability and data collection on demographic statistics obtained using reconstructive techniques. We agree that these are issues that seagrass ecologists must face in evaluating seagrass dynamics at the landscape level. Unfortunately, the conclusions of Jensen et al. (1996) are based on repeated misuse of statistical analyses and artifacts of sample processing. The authors report that approximately $40 \%$ of the shoots in their (we assume processed) samples were 'found to be unattached'. This statement is misleading. What is actually being reported is that during their processing of core samples, $40 \%$ of the shoots were broken from their rhizome attachment. The authors then argue that breakage of shoots during sampling collection may bias the results if older, longer, shoots are more likely to break than younger, shorter ones This is a possibility worth testing; however, it is not a problem of reconstructive techniques, but of how the samples were handled. The number of shoots that break from their rhizome attachments can be minimized by laying cores on their sides and carefully removing the sediments using a water jet. Using this method reduces the proportion of broken Thalassia testudinum shoots from about $25 \%$ to about $10 \%$ of the total sample (Duarte unpubl.).

The evaluation presented by Jensen et al. (1996) on the effects of what they term is 'data censoring' by exclusion of the unattached shoots is derived using a series of inappropriate statistical comparisons of population characteristics for attached shoot versus total (includes attached and unattached) shoots. The attached-shoot population is a subsample of the totalshoot population, and therefore is not an independent sample. The null hypothesis of the KolmogorovSmirnov 2-sample test used by Jensen et al. (1996) is identity in distribution for the 2 samples (Sokal \& RohIf 1981). Attached and total short-shoots came from the same sample. According to the authors, approximately $60 \%$ of the total population is comprised of the attached shoots, against which they make pairwise comparisons. This nonindependence of samples violates the most fundamental of statistical assumptions and invalidates any evaluation of statistical significance for attached vs total shoots (Tables 1 \& 3 in Jensen et al. 1996). In addition, in Table 3 of Jensen et al. (1996) the authors present multiple pairwise comparisons of the attached and total age distributions from 3 sampling sites using the Kolmogorov-Smirnov test of similarity. The authors indicate that 6 of the 16 comparisons indicate that the age distributions are significantly different using $\alpha=0.05$. They failed to recognize that these pairwise comparisons are not independent ( 2 of the 'significantly different' compar- 
isons were between subsamples of single samples] and that the use of $\alpha=0.05$ is inappropriate. Because multiple pairwise comparisons were conducted on the same data, an adjustment designed to limit overall experimentwise error rate such as the Bonferroni inequality ( $\alpha^{\prime}=\alpha / n$, where $n$ is the number of tests conducted; Glantz 1992) must be used to determine the $p$ values. The proper $\mathrm{p}$ value of 0.003 produces critical $D$ values that are $33 \%$ higher $\left(D_{0003}=1.803 / \sqrt{ } n\right.$ versus $D_{005}=1.358 \mathrm{~V} n$; Sokal \& Rohlf 1981) than the values used by Jensen et al. (1996), reducing the number of significant differences among their comparisons.

In addition to the improper use of statistical analyses, the figures and comparative discussion of mean and maximum ages for the attached and total shoots from the 3 sites sampled by Jensen et al. (1996) are also misleading. Because the distributions of shoot age are strongly skewed (see Fig. 3 in Jensen et al. 1996), mean values are an inappropriate measure of central tendency, i.e. they are greatly influenced by the few very old shoots encountered (Glantz 1992). The maximum age in a random sample from such skewed distributions may increase with sample size. Hence, a larger sample size (e.g. total vs attached shoots) will result in more old shoots being included and, thus, a larger mean shoot age, even if the underlying shoot age distribution was exactly the same. The differences in mean shoot age, discussed as 'indicative that the choice of sampling station will influence the interpretation of the demographics of the sampled population', may simply reflect differences in sample size (i.e. number of shoots aged). A more appropriate comparison of the central tendency in shoot age distributions with differing sample sizes should be based on the median (Glantz 1992), and must include proper statistical comparisons (e.g. attached vs attached) to test whether differences in descriptors of the age distribution were significantly different between stations. This multitude of fundamental errors undermines the validity of the conclusions of Jensen et al. (1996)

Test conclusions and recommended alternative population models. The conclusions and recommendations made by Jensen et al. (1996) are inconsistent with existing knowledge or information presented in papers they cited, and they are inappropriate for a long-lived species such as Thalassia testudinum. Durako (1994) demonstrated significant interannual variability in mortality and recruitment rates (1989 vs 1990), indicative that the assumption of constant mortality rates and recruitment rates necessary for longerterm forecasts do not hold for the Florida Bay seagrasses. Hence, the 'test' of the predictions made by Jensen et al. (1996) is flawed by testing a forecast with a 1 yr anticipation, 4 yr later, and then additionally misinterpreting the prediction values which were formu- lated for 3 different basins, not as ranges for Rabbit Key Basin. Moreover, Durako (1994) described increased mortality and recruitment rates in response to seagrass die-off in all 3 Florida Bay basins. Durako (1994) also suggested that recruitment rates were likely to again increase in 1991, because the density of rhizome apexes (the origin of all new shoots) was significantly (5-fold) greater in 1990 than in 1989, leading to the expectation of greater recruitment rates in 1991

A test of the influence of spatial heterogeneity on demographic statistics, and hence of the importance of spatial variability, must necessarily be based on a statistical comparison. The gross recruitment and mortality rates in Table 2 of Jensen et al. (1996) are not significantly different among sites for total shoots nor for attached shoots. In addition, the maximum shoot ages and estimates of gross recruitment and total shoot mortality (versus mortality of cohorts) in this table are quite similar to those reported by Durako (1994) for Rabbit Key Basin. The similarity of the results obtained from completely different stations at different times (years and months) renders invalid the claim by Jensen et al. (1996) that their results demonstrate that the choice of sampling station significantly biases the calculation of demographic statistics. Durako (1994) also sampled at a spatial scale much larger than that used by Jensen et al. (1996). Accordingly, the results of the earlier study cannot be dependent on the same spatial scale of sampling as argued by Jensen et al. (1996). Thus, in contrast to the conclusions of Jensen et al. (1996), their data provide little evidence that spatial variability is an important factor potentially biasing the demographic predictions.

There were very few studies of seagrass demography before reconstructive techniques were applied (see review by Harrison 1990). A major reason for this is that direct measurements of seagrass birth and mortality, by following individual shoots through time, are cumbersome, time-consuming, and Jogistically unfeasible for long-lived species. Hence, postulating the use of data-intensive models, such as an age-structured projection matrix, without a rigorous assessment of their utility is highly speculative. Although Jensen et al. (1996) advocate the use of age-structured matrix population models in seagrass demography (and use an unpublished citation as support), they also recognize that age-structured models for seagrasses cannot be accurately parameterized at this time. Age-structured matrix models are appealing because the greater detail they require provides the scientist with the rewarding feeling of greater understanding. We contend, however, that assessment and prediction, rather than understanding, are more frequently the primary goals for seagrass ecologists, particularly on issues where there is an explicit demand for status and trend 
analysis by resource managers. The best model is, therefore, that which provides the best assessment or predictions, regardless of how much detail it contains. The model choice should also allow for widespread applicability without the need for extensive local resources to support academic research.

The age-structured approach may be better suited for species whose shoot life span is short (e.g. Halodule, Halophila, and Zostera spp.), for which the application of reconstructive age determinations is also not practical. Because the use of age-structured matrix population models involves estimation of age-dependent transition probabilities, which requires identification of shoots as they recruit to the population and following them through time, they cannot be practically applied to seagrasses with long-lived short-shoots such as Thalassia (>10 yr) and Posidonia spp. (>30 yr). Also, age distributions of the shoots for these species cannot be ascertained without destructive sampling. It may be feasible, however, to nondestructively determine age distributions for some longer-lived genera (e.g. Thalassodendron and Amphibolis) which produce shortshoots that extend into the water column.

Caswell (1989) points out that in matrix population models, age is an 'inadequate $i$-state variable' (i.e. a variable used to characterize individuals within a population) for species which exhibit multiple modes of reproduction (such as Thalassia testudinum; Tomlinson 1974, Zieman 1975, Durako \& Moffler 1987). In these cases, the probability of survival to the next age class often differs markedly (3- to 30-fold; cf. Cook 1985) depending on whether individuals were produced vegetatively or from seed. The inadequacy of age-specific models for these species coupled with the lack of any obvious alternative $i$-state variables (e.g. size or physiological metrics), which are not subject to the same complications caused by multiple modes of reproduction, underscores additional obstacles in applying these alternative methods. We agree that further examination of age-specific survival and fecundity schedules for long-lived seagrasses is needed, but we also feel that the use of reconstructive techniques currently offers the only practical alternative to assessing seagrass demography for long-lived species, thereby providing the knowledge necessary to assess and manage these important coastal ecosystems. Had Jensen et al. (1996) considered the age-specific matrix models in light of the life history attributes of Thalassia testudinum, they undoubtedly would have recognized the inherent inadequacy of alternative age-based models, in this context. We conclude by encouraging efforts to provide rigorous, unbiased tests of models of seagrass population dynamics, while warning our peers of the limitations associated with developing models too demanding or inappropriate for widespread application.

\section{LITERATURE CITED}

Brouns JJWM (1985) The plastochrone interval method for the study of the productivity of seagrasses; possibilities and limitations. Aquat Bot 21:71-88

Caswell H (1989) Matrix population models: construction, analysis, and interpretation. Sinauer Assoc, Sunderland

Cook RE (1985) Growth and development of clonal plant populations. In: Jackson JBC, Buss LW, Cook RE (eds) Population biology and evolution of clonal organisms. Yale Univ Press, New Haven, CT, p 259-296

Cox DR, Oakes D (1984) Analysis of survival data. Chapman and Hall, New York

Duarte CM, Sand-Jensen K (1990) Seagrass colonization: b1omass development and shoot demography in Cymodocea nodosa patches. Mar Ecol Prog Ser 67:97-103

Duarte CM, Marbá N, Agawin N, Cebrián J, Enriquez $S$, Fortes MD, Gallegos ME, Merino M, Olesen B, SandJensen K, Uri J, Vermaat J (1994) Reconstruction of seagrass dynamics: age determinations and associated tools for the seagrass ecologist. Mar Ecol Prog Ser 107: $195-209$

Durako MJ (1994) Seagrass die-off in Florida Bay: changes in shoot demographic characteristics and population dynamics in Thalassia testudinum. Mar Ecol Prog Ser 110:59-66

Durako MJ (1995) Indicators of seagrass ecological condition: an assessment based on spatial and temporal changes associated with the mass mortality of the tropical seagrass Thalassia testudinum. In: Dyer KR, Orth RJ (eds) Changes in fluxes in estuaries: implications for science to management. Olsen and Olsen, Fredensborg, p 261-266

Durako MJ, Barber TR, Bugden JBC, Carlson PR, Fourqurean JW, Jones RD, Porter D, Robblee MB, Yarbro LA, Zieman RT, Zieman JC (1992) Seagrass die-off in Florida Bay. In: Jacobsen JD (ed) Proc 1992 Symp Gulf of Mexico. US EPA, Tarpon Springs, FL, p 14-15

Durako MJ, Moffler MD (1987) Factors affecting the reproductive ecology of Thalassia testudinum (Hydrocharitaceae). Aquat Bot 27:79-95

Erickson RO, Michelini FJ (1957) The plastochron index. Am J Bot 44:297-305

Gallegos ME, Merino M. Marbá N, Duarte CM (1992) Flowering of Thalassia testudinum Banks ex König in the Mexican Caribbean: age-dependence and interannual variability. Aquat Bot 43:249-255

Gallegos ME, Merino M, Marbá N, Duarte CM (1993) Biomass and dynamics of Thalassia testudinum in the Mexican Caribbean: elucidating rhizome growth. Mar Ecol Prog Ser 95:185-192

Glantz SA (1992) Primer of biostatistics. McGraw-Hill, New York

Jensen SL, Robbins BD, Bell SS (1996) Predicting population decline: seagrass demographics and the reconstructive technique. Mar Ecol Prog Ser 136:267-276

Harnson PG (1990) Population dynamics In: Phillips RC, McRoy CP (eds) Seagrass research methods. Unesco, Paris, p 27-32

Marbá N, Gallegos ME, Merino M, Duarte CM (1994) Vertical growth of Thalassia testudinum: seasonal and interannual variability. Aquat Bot 47:1-11

Patriquin D (1973) Estimation of growth rate, production and age of the marine angiosperm Thalassia testudinum König. Caribb J Sc1 13:111-123

Ricker WE (1975) Computation and interpretation of biological statistics of fish populations. Bull Fish Res Bid Can 191

Robblee MB, Barber TR, Carlson PR, Durako MJ, Fourqurean JW, Muehlstein LK, Porter D, Robblee MB, Yarbro LA, 
Zieman RT, Zieman JC (1991) Mass mortality of the tropical seagrass Thalassia testudinum in Florida Bay (USA). Mar Ecol Prog Ser 71:297-299

Sarukhán J, Piñero D, Martínez-Ramos M (1985) Plant demography: a community-level interpretation. In: White $J$ (ed) Studies on plant demography-a Festschrift for John L. Harper. Academic Press, New York, p 17-31

Sokal RR, Rohlf FJ (1981) Biometry. WH Freeman, San Francisco

Tomlinson PB (1974) Vegetative morphology and meristem dependence-the foundation of productivity in sea- grasses. Aquaculture 4:107-130

Van Tussenbroek BI (1994a) Aspects of the reproductive ecology of Thalassia testudinum in Puerto Morelos reef lagoon, Mexico. Bot Mar 37:413-419

Van Tussenbroek BI (1994b) The impact of hurricane Gilbert on the vegetative development of Thalassia testudinum in Puerto Morelos coral reef lagoon, Mexico: a retrospective study. Bot Mar 37:421-428

Zieman JC, Fourqurean JW, Iverson RL (1989) Distribution, abundance and productivity of seagrasses and macroalgae in Florida Bay. Bull Mar Sci 44:292-311 